\title{
Children's graphic representation as a language and its role in preschool education under a whole-child approach
}

\author{
Paula Cristiane Strina Juliasz ${ }^{\mathrm{a}, *}$ \\ ${ }^{a}$ PhD of the Geography Department of Philosophy, Languages and Human Sciences of the University of Sao Paulo (USP), \\ - paulacsj@usp.br \\ * Corresponding author
}

\begin{abstract}
The objective of the present study is to analyze the drawings of the space by children as a representation system involving spatial thinking and higher mental functions such as memory and imagination. Our analysis is based on the historical-cultural theory on human development and on studies about the relation between spatial thinking and the graphic representation of space. Drawing is a language, the first written production by children and is characterized by elements associated with the cognition, culture, motor development and affectivity. Three elements were considered in our analysis: a) the creation of graphic equivalents; b) volume translation; c) perspective. We understand that the topological and projective notions must be based on the development of higher mental functions that mobilize the creation activity, such as memory and imagination, since such these functions constitute instruments to access systematized knowledge.
\end{abstract}

Keywords: school cartography, geography, spatial thinking

\section{Introduction}

Over the last decades, several studies on spatial representations by children and the development of spatial thinking have been published; however, the literature lacks information on the development of spatial notions and geographic thematics in preschool education, mainly regarding 4- to 5-year-old children. The absence of theoretical and methodological referentials can lead to the dislocation of practices intended to older students to preschool students, and, consequently, the cognitive, social and affective development of this age group can be disregarded.

Aiming at stablishing theoretical and methodological referentials for this segment and to broaden your knowledge on spatial representation by children based on the historical-cultural theory, we developed the study entitled Drawing as spatial thinking representation system: a cultural and historical approach in school cartography.

The study was based on the following question: how can higher mental functions and creation activity be involved in the formation of a logos associated with topological and projective relations? To answer this question, the present study aims analyzing drawings of space by children, regarding them as representation systems that involve the development of spatial thinking and higher mental functions, such as memory and imagination. For this, we analyzed human development based on the historicalcultural theory and the relation between spatial thinking and graphic representation of space in concrete educational actions.

This question comprises the historical and cultural conception that the development of a person from the development of learning, and pedagogical outcomes that can create learning conditions and subsequent, development conditions, based on the relationship between thinking and language (Wiegand, 2006).

\section{Children and Spatial Thinking}

\subsection{Knowledge and School Education}

School contributes for the relations between subjects and knowledge in the sense of cultural and historical development; therefore, since early age children can be mobilized to think about space and its organization in a problematizing way.

It is important to understand that, in what regards school education, the conceptions about knowledge elaborations and children are fundamental for addressing human development and educational activities, since the formation of a social individual involves the triad teaching-learning-development. An environment that provides conditions for the expression. of thoughts, creation activities and dialogue correspond to the idea of the school as a space for learning and human development, where culture is an instrument to access systematized knowledge, enriching and modifying everyday life and past experience. From this perspective, the school is a space to broaden experience and cognitive activities developed in the everyday practice, which is turn is broadened by spatial thinking through the elaboration of systematized knowledge and the active action of the subject.

The conception of childhood is a subject of investigation in different areas, such as psychology and sociology, since the ideas regarding children and their social groups have undergone transformations throughout history, 
considering that the conception of society has also been constantly transformed. Therefore, assuming that children are social beings, we cannot take them as mere biological evolution, underestimating their historical and cultural construction in society.

It is critical to analyze the relation between children and preschool education to understand the development of social individuals in knowledge elaboration conditions. Preschool education is a segment of the Brazilian school system and is mandatory for children at the age of four. This segment provides children with the first contacts with systematized knowledge and with opportunities to express ideas and feelings about a particular subject, since they can ask questions, share readings, and express emoticons through play, sculptures and drawings, i.e., children start to experience artistic, philosophic and scientific activities. The relation between the child and the environment as a unit corresponds to the notion of experience by Vygotsky (2018), which reflects how the child attributes meaning and interacts affectively with a particular event. Based on the historical and dialectical materialism, Vygotsky incorporates the history and the culture of the psychology research emphasizing the importance of the social relations converted into mental functions. Thus, the cultural and historical production of tools and signs affects and constitutes the conditions for the existence of the subject, who in turn, as a historical being, transforms such conditions and is transformed by them; therefore, the processes of development and learning are not coincident, the former follows the latter (Vigotski, 2012).

If we understand that the school environment provides conditions for the children to develop their higher mental functions and to broaden their experience, the intentional activities involving spatial representations can broaden spatial thinking in preschool education, since this way o thinking allows the children to observe, reflect upon and express the conditions and connections of the space. Spatial thinking is a cognitive activity developed in the everyday life and is systematized through the elaborated knowledge.

Such cognitive activity permeates the different disciplines throughout the school trajectory and therefore is broadened through the knowledge constructed since preschool education. It consists in a cognitive process that integrates the different segments of basic education, and becomes increasingly complex as the different areas and spatial/cartographic representations are learnt by the subjects.

Through geography learning, the ways of thinking the space using concept and spatial notions such as location and distance are broadened. Analyzing spatial dimensions requires a way of thinking that is inherent to geography, since it involves thinking about the concrete, abstract and the spatial setting, revealing the epistemological and ontological importance of geographic science knowledge while addressing the scientific knowledge and the formation of the subject, the social being.

In preschool education, the elaborated knowledge is not associated with disciplines as in the subsequent stages of basic education; rather, it refers to elementary notions developed for the formation of the social being based on the ontological role of knowledge. Therefore, it is critical to understand the development of higher mental functions in the creation activity of the children in their spatial representation and how They construct intellectual mediations regarding the space, and the topological and projective relations of the space.

In this sense, we address the ontological foundations of a historical and social conception of the social being formation and their relation with knowledge, since in the social life of the human reality reproduction which is characterized by the transformation of both the reality and the individuals in an attempt to satisfy their needs, the appropriation of the cultural products of the human activity becomes the pillar of the educational practice.

In this sense, spatial thinking can be broadened through geography activities by mobilizing the spatial relations and the higher mental functions, creating conditions for human development and for the appropriation of objectivated and historicized cultural instruments.

\subsection{Memory and Imagination}

Elaborating, learning or getting acquainted with existing knowledge involves a human and conscious activity, an accumulation of cultural instruments produced by humanity. Learning is a human activity of cultural signs appropriation that involves the development of higher mental functions. According to Vygotsky (2009) and Luria (2001), these functions are produced by each individual in a different way because of the interiorization of cultural instruments.

Intentional activities in which the children can draw their space or recreate actions by playing involve the development and mobilization of higher mental functions, such as memory and imagination. These functions are called 'higher' functions for corresponding to mechanisms learned in the relations with other children and adults through speech and thinking. Memory and thinking are developed throughout school life and through intentional activities, in which the speech and hearing are actions of dialogic relations that involve voluntary attention and, in turn, influence the development of thinking and memory. It is important to understand the dialectic relation between speech and thinking, since one is a dimension of the other, speech is thinking, but thinking is also speech. Speech is the main symbolic instrument for the humanity.

Throughout human development, memory is activated and modified and differentiated, the brain combines what is stored and what it can create. Human activity is not limited to the reproduction of facts or lived impressions, but it creates images and new actions with combinatory and creating functions (Vygotsky, 2011).

This activity corresponds to the so-called imagination, the basis of the creation activity that embodies the meaning of artistic, technical and scientific creation. All the things created by humanity, the whole cultural world is differentiated from the natural world, all these things are product of imagination and human creation. To create, one needs to imagine. In preschool education, the children's 
ability to create, the promotion of such ability and its importance in the general development of the children constitute the pillars for intentional activities that combine imagination and memory. Games and plays provide the children with the opportunity to elaborate experience in a creative way, constructing new realities according to their emoticons and needs.

The creation activity is directly associated with the richness and the variety of an experience, since such experience is the material that produces fantasy or imagination. Thus, to provide children with a sound basis for the creation activity, the experience must be broadened, since imagination and memory together trigger and potentialize the creation capacity. Perception also influences imagination, as everything children see and hear support further creations.

Imagination is supported by experience in a dialectic sense. Vygotsky (2011) established four main relations between fantasy and reality: 1) the richer the experience, the greater the amount of material available for imagination; 2) the relation between the final fantasy product and someone's else experience, for example, the comprehension of a historical event, not directly experienced, such as the French Revolution; 3) emotional factors, which, according to the author, aggregates to the image, combined and determined by the mood, in addition to collective emotional signs, culturally established, such as colors that transmit particular feelings; 4) found mainly in artwork, fantasy is related with something new and distant from experience. Understanding the combinations between perception, memory and imagination in the creation activity during childhood allows us to identify what mechanisms can be mobilized in our teaching practice in what regards spatial thinking development and scientific concepts. Imagination and memory are higher mental functions representing the foundations for culture appropriation and the essence of educational practice.

It is critical to understand human development in the field of children's spatial representations and relations, since we consider the conception of longitudinal development and spatial thinking broadening through geographic knowledge and spatial and cartographic representations. Here, spatial thinking is conceived as human cognitive activity, ontological foundation of knowledge.

We consider the relation between memory and imagination and the connections between speech and thinking in the development of space graphic representation by children. Drawing is a way to concretize spatial thinking; therefore, we have a question to be considered: how can higher mental functions and creation activity be involved in the formation of a logos associated with topological and projective relations?

In early age, children become aware of their body and realize it is part of a whole. They start using referentials and space orientation with the notions of right/left, on/under, in front/behind. Such basic notions and its forms of representation can be mobilized through drawings, scale models and gestures as part of intentional learning activities in preschool education.
The ways to reflect upon space and time are part of everyday life, the activities that correspond to cultural everyday or non-everyday actions, and that can be also scientific, philosophical and artistic. The development of such notions by the child involves a particular way of thinking - spatial thinking - and requires investigations about teaching methodologies that, in turn, must consider the importance of the environment in the child's development (Juliasz, 2018; Catling \& Martin, 2011). It is important to emphasize that, while not called 'geography" in the preschool curriculum; it is present in the development of the notions of space and time.

This knowledge systematizes the reading of the world, the understanding of spatial formation, the production processes and the relations between the social dimensions of people's lives. The analysis of a spatial problem requires answering the question 'where?' using the geographic principles (location, distance, extension, distribution and scale), since while analyzing a particular element of reality through geography, we locate spatial objects, their distribution and distance and limit their extension according to a possible scale, relating the spatial objects in their totality (Gersmehl, 2008; Helfenbein, 2010).

Through its principles, geographic education contributes to the recognition of cultural dimensions of different places and of the interaction between the different societies and the environment (Catling \& Willy, 2018). Therefore, we work with temporal and spatial scales to recognize, understand and analyze the space generated by social relations.

\section{Research practice}

The present research was developed through the analysis of graphic productions, of the speech and gestures of children during geography learning activities carried out in previous studies (Juliasz, 2021) developed in 3 preschool education schools with approximately 90 children aged between 4 and 5 years old. These activities formed a collection of records of 25 teaching situations, which have been constantly analyzed, allowing the establishment of references on drawing as a system of representation of space. This collection made it possible to analyze how children in this age group deal with situations that mobilize spatial relationships and the relationships between drawing and representation of space.

The research is included in the field of cartography, constituting an interface between education, geography and cartography. This is a qualitative research, since the activities and drawings are analyzed based on the culturalhistorical theory and on theories regarding drawing development. We considered the following criteria to analyze drawing as space representation: a) creation of graphic equivalents; b) volume translation; c) perspective. Therefore, preschool education must provide children with opportunities to experience activities aimed at broadening the relation between spatial thinking and language (speech and drawing). 


\section{Drawing: space representation system}

According to historical and cultural studies, drawing consists in a language, the first written production of a child, and is characterized by elements of cognition, culture, motor development and affectivity. It is not merely the domain of the material, a motor activity; rather, it involves learning, historicity and the graphic representation of thinking and spatial information.

Luria (2001) states that, in children, written representation antecedes the knowledge about letters. In the content of school cartography, the drawing is regarded the first graphic expression of spatial thinking, it is the onset of spatial representation that antecedes knowledge about cartography, signs, map elements, projection principles and geometric concepts (dot, line and area).

Luria (2001) investigated how children gradually become aware of writing as a way to register and communicate. The author reported that some children traced random lines, without connections with the idea to be represented. This unintentional and meaningless writing was an attempt to imitate writing symbols, with no relation between writing, naming and memory.

In our research, we asked the children to draw a map of the way from the school gate to the classroom, and we observed that the graphic productions lacked meaning and were a graphic imitation of a map, i.e., a map with dots, lines and areas. When the children were asked (Figure 1) what they had drawn, they answered: the map. However, we could not be satisfied because the children answered the word 'map', since it would not mean they would know the function and the elements of a map. It would be very optimistic to imply that tracing adult-like lines would mean a conscious ability to draw a map, since the map is imbued with meaning and spatial knowledge. A map without spatial meaning requires new teaching interventions and activities that bring meaning to the children.

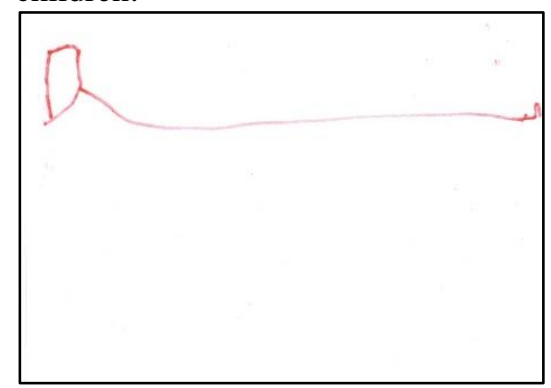

Figure 1. "Map" Drawing

Writing, while the representation of a thought, interferes in it as the functioning of entities in a phrase requires attention on what is communicated and registered. According to Olson (1997, p. 298), "Writing and reading played a critical role in producing the shift from thinking about things to thinking about representations of those things, that is, thinking about thought". Thus, we understand that the map or drawing reveal and interfere in the way we think about space and in the way we think about its representation.

Studies on drawings as space representations require the understanding of two elements: representation and mind formation. The representation is associated with thinking, it is broad and based on: a system of concepts, such as location and size; on the relation between the units and the whole represented; and on the mental image. A drawing produced from a spatial problem carries the meaning of the portrayed space.

This research has helped to clarify at what point drawing becomes space representation. In preschool education, when drawing is to be preceded by intentionality, three elements must be considered: a) creation of graphic equivalents; b) volume translation; c) perspective.

Graphic equivalent is the term used to describe the graphic element created to represent a real object. Observing how the graphic equivalents are created by children is a way to understand the ways They deal with problems involving volume and perspective. Drawings are equivalent, contain properties of the original object - what is to be represented - and a particular convention stipulates what should be included or not. They are also ambiguous and their relation vary according to what they symbolize (Goodnow, 1979). While representing objects, people, environments and maps by drawing, children stablish limits between the units of a whole, i.e., the whole is comprised of parts, which become more detailed according to the intentionality of the child to name and represent them graphically. To analyze changes in the lines traced by children - not from a linear perspective, but from the less representative to the more representative, we need to know what they intend to draw and what graphic equivalents are more frequently repeated. This way we can identity the new perspectives graphic equivalents they used in their productions. In this sense, we identify changes as a space representation system, in which old graphic equivalents coexist with new ones while spatial thinking is concomitantly broadened.

The translation of volume is associated to the moment when children try to figure out how to express tridimensional spaces or objects according to their intentionality in creating graphic equivalents. It is the projection of space volume in graphic value, a bidimensional one, and such projection can have different characteristics: a) one-point perspective, usually frontal; b) different perspective points coexist with syncretic combinations and rebatements; c) depth perspective; d) coordination of different plans, achieving perspective in the representation.

In an activity where the children observed and handled two scale models of a children's story (SANTOS, 2000), we could note that the children drew the characters' spaces from two points of perspective: a) frontal view; b) vertical view; and c) mixed view. In Figure 2, the frontal view is used to represent all the elements, in Figure 3, the perspective points are mixed: the rivers are represented in a vertical view (A), while other elements such as houses, cars and mountains were drawn from a frontal perspective. In Figure 4, the vertical view predominates in the representation of the rivers (A), the bridge (B) the cars (C), and the rebatement of the wheels. 


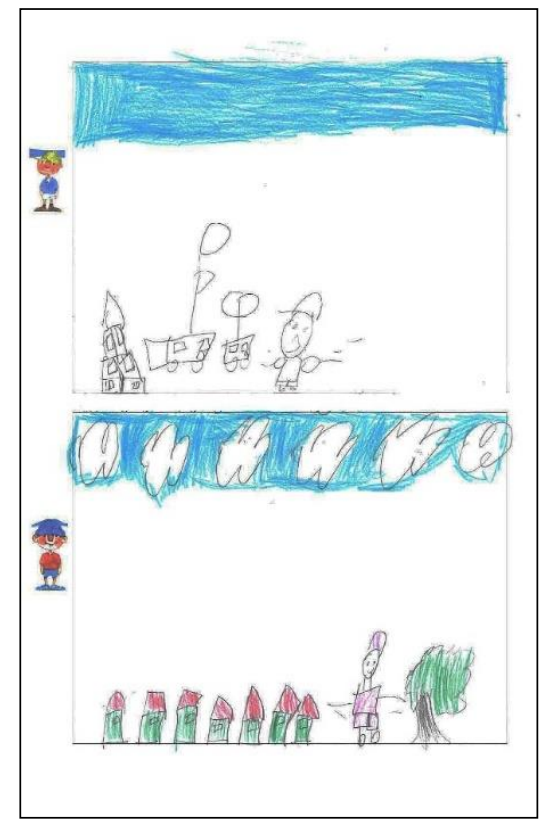

Figure 2. One-point perspective

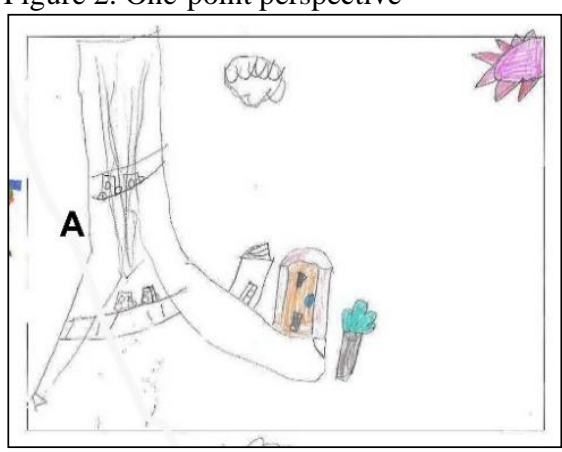

Figure 3. Different points of view

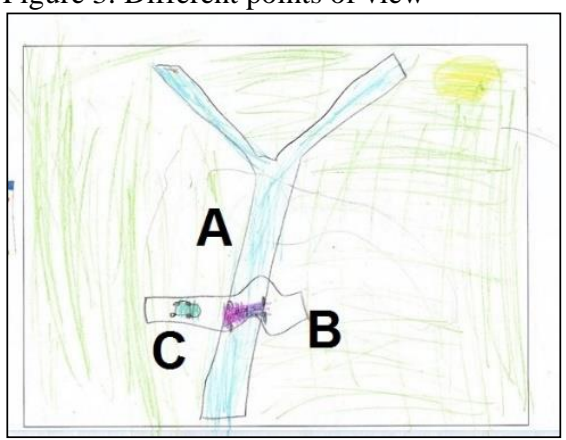

Figure 4. Vertical perspective

The one-point perspective is associated with juxtaposition and the syncretic conjunction (rebatement and transparency) is based on superposition, the materialization of the action and is associated with coordination, interruption-continuity of positions and plans, e.g., a knife cutting a fruit.

A skyline or a band of clouds, a groundline or a green roof introduce, sometimes precociously, the three bands of graphic structuration (Greig, 2004). Recognizing the establishment of the three bands (sky, Middle and ground) is fundamental for the teacher or researcher who wants to analyze space representation by children, since it is possible to identify the graphic equivalents already created, the most used ones, possible syncretic combinations and perspectives. The relations between the elements of a particular drawing provides support for successive advances in space representation, considering that there is a set being represented and communicated by the child. In Figure 5, we note that the child stablished the way from the gate to the classroom using a baseline with two elements - a starting point, the school gate and the arrival point, the school building -, between them three swimming pools from a vertical perspective and above this middle band the child drew the skyline and the sun. Thus, we see the combination of different perspectives and topological relations. While drawing spaces they have experienced, children mobilize memory and attention, since the elements are recreated and represented in the graphic space.

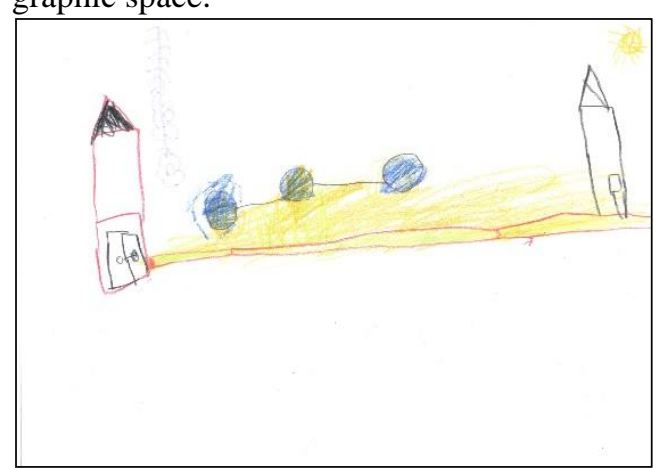

Figure 5. Drawing with groundline and skyline

The recognition of a baseline allows the development of topological relations of neighborhood and the location of elements in the same plan. The skyline consists in a very expressive value of fusion, contact, barrier or conflict in the spatial representations. In this sense, we seek to understand the use of lines by the children, how such use is related with spatial thinking abilities and the use of a baseline to mobilize perspective points other than the frontal one.

In activities using scale models, we observed the importance of analyzing the arrangement of the elements by the children and the use of a base plan as an instrument for the problematization of space representation. We verified that some children anticipate the projective representation of the perspective from above. The projective relations are operated from the perspective and allow the children to understand that changes do not alter the equivalence of the position of objects in space; therefore, the coordination of different perspective points starts to occur to locate a particular object in space. Figure 6 shows a tridimensional representation in a sequence of activities about the city. From this representation, the children discussed and observed the position of the elements and made a graphic representation from a problem, the base plan. In Figure 7, the child represented a vertical perspective of the park with a soccer field, and in Figure8 we can see the rebatement of the houses, showing a frontal perspective. 


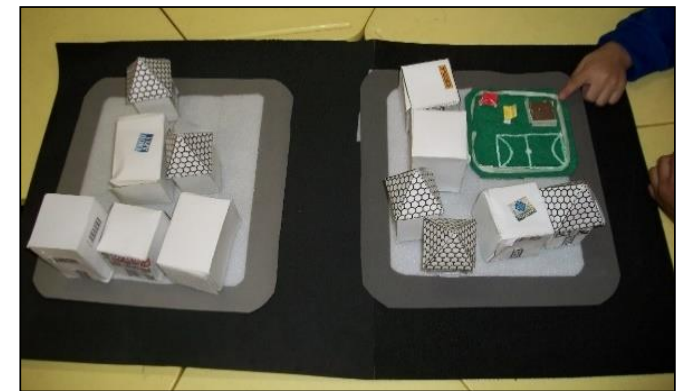

Figure 6. Tridimensional Representation

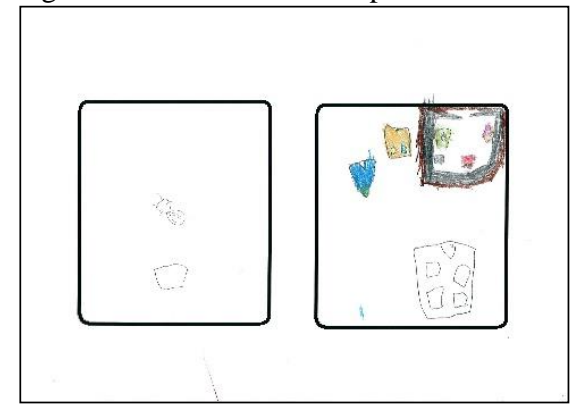

Figure 7. Drawing of the park - above perspective

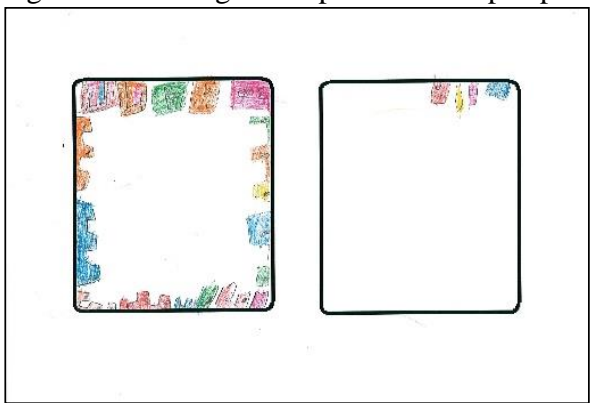

Figure 8. Rebatement of the houses in the block

Both the cartography and the drawing present the same nature, the graphic representation, and this is why we emphasize that the drawing is part of cartographic literacy, the first piece of writing about space. Cartography and drawing are representation systems with their own peculiarities, since they have different purposes and aim different readers. A drawing of a particular environment produced by a child intends to communicate something about the space, and the map produced by a cartographer also emits some information about space.

The map has its precision, it is based on mathematics, composed by a grid of coordinates and particular precisions; however, we should not take it regardless the reality it represents, i.e., above all, the map is a representation. A drawing can be a product of imagination, reflecting the coordination of a perspective and the correspondence of a graphic element to an imagined or real object. Thus, a map and a drawing of space are two representation systems inserted in culture.

In what regards learning activities problematizing the organization of space, thinking about the space involves perceptions and memories while differentiated higher mental functions that act along with inferences, generalizations and descriptions. In what regards children's cartography, mainly the drawing of the space, there is a relation between spatial thinking and the graphic language, i.e., the representation and the mind inserted in culture, in accordance with Olson (1997, p. 298), who regards the drawing of space as writing:

"Mind, in part, is a cultural artifact, a set of concepts, formed and shaped in dealing with the products of literate activities. These artifacts are as much a part of the world, as the stars and stones with which they once confused. Inventing these artifacts put an indelible stamp on the history of culture, learning how to cope with them puts a indelible stamp on human cognition."

Drawing is the product of the human creation activity, based on the relation between the creator's memory and imagination and on the verbal language. In this sense, we can note that children construct narratives upon their graphic productions (Vigotski, 2011). The speech is an essential element in the drawing symbolic representation, considering that, at a certain moment, children realize that the lines traced by them have meaning and imply a context. Speech plays a critical role in the formation of the subject and of spatial thinking, since naming can follow the act of drawing.

We understand the importance of creating a logos regarding the topological and projective relations that permeate teaching activities, considering the relations between speech, drawing and spatial thinking. These are complex elements: a) the speech is not an empty sound, it brings generalizations through words; b) drawing involves higher mental functions and corresponds to the expression of human creation activity; c) spatial thinking comprises human cognitive activities regarding the notions of space and time, such as simultaneity and location.

In this sense, speech, imagination, memory and thinking are developed through intentional activities that mobilize spatial knowledge via graphic representation. Considering the initial question: how can higher mental functions and creation activity be involved in the construction of a logos regarding topological and projective relations? The topological notions must be based on the development of higher mental functions, e.g., memory, since these functions are instruments to access systematized knowledge. For children, the determination of the concept, the object of thinking, is stablished by the memory, not by the logic structure of the concepts. In the determination of the concept, thinking is mostly constituted by memory, and the concreteness of children's thinking, its syncretic character is also based on memories (Vigotski, 1998, p. 44).

It is important to relate memory to another mental function: imagination. Children imagine by creating new combinations with memory data, and the educational environment - in this case preschool education - must provide opportunities for the development of scientific contents under a whole-child approach.

\section{Final Considerations}

It is critical to think about strategies and activities to broaden spatial knowledge for the development of basic notions of location. In this sense, our studies demonstrate that the activities must be intentional, providing the children with the opportunity to acquire and access systematized knowledge. 
Children's drawings of the space introduce notions of representation, awareness and intentionality. In geography, it is possible to infer that space comprises a system characterized by parts of a whole, and such parts must be analyzed and seen as simultaneous and successive. Using pencil and paper as resources to draw the everyday life space where they live and play requires the children to activate their imagination and memory in an intentional way.

The knowledge we acquire and promote in the classroom in imbued with social history and is highly complex in terms of space and cognitive activities. Preschool education bridges personal and scientific knowledge, including cultural instruments and subsidizing children's development and access to knowledge, which is a fundamental children's right as historical and social individuals.

\section{References}

Catling, S \& Willy, T (2018) Understanding and Teaching Primary Geography. London: Sage.

Catling, S. \& Martin, F. (2011) Contesting powerful knowledge: the primary geography curriculum as an articulation between academic and children's (ethnogeographies. Curriculum Journal, 22(3), 317-335.

Gersmehl, P. J. (2008) Teaching Geography. New York: Guilford Press.

Goodnow, J. (1979) Desenho de Crianças. Lisboa: Moraes Editores. 1979.

Greig, P. (2004) A criança e seu desenho: o nascimento da arte e da escrita. Porto Alegre: Artmed.

Helfenbein, R J. (2010) Thinking through scale: Critical Geography and curriculum spaces. In Maleviski, E. (ed.): Curriculum studies handbook: the next moment. New York: Routledge, pp. 304-317.

Juliasz, P. C. S. (2021) The role of language in the construction of spatial thinking in Early Childhood Education. In Castellar, S. M. V.; Pereira-Garrido, M. \& Lache, N. M. (ed.) Geographical Reasoning and Learning Perspectives on curriculum and cartography from South America. Springer International Publishing, pp. 1-23.

Juliasz, P. C. S. (2018). Spatial thinking in preschool education: the construction of geographic knowledge. Boletim Paulista de Geografia (BPG), 99, 231-250.

Luria, A. R. (2001) O desenvolvimento da escrita na criança. In Vigotski, L. S.; Luria, A. R.; Leontiev, A. N. (ed.) Linguagem, desenvolvimento e aprendizagem. São Paulo: Ícone. pp. 143 - 189.

Olson, D. (1997) O mundo no papel: as implicações conceituais e cognitivas da leitura e da escrita. São Paulo: Editora Ática.

Santos, J. R. (2000) A Pirilampéia e os dois meninos de Tatipurum. São Paulo: Editora Ática.

Vigotski, L. S. (2018) Sete aulas de L. S. Vigotski sobre os fundamentos da pedologia. Rio de Janeiro: E-Papers.
Vygotsky, L. S. (2011) La imaginación y el arte en la infancia. Madri: Akal.

Vigotski, L. S. (1998) O desenvolvimento psicológico na infância. São Paulo: Martins Fontes.

Vigotski, L. S. (2009) A construção do pensamento e da linguagem. São Paulo: Editora WMF Martins Fontes.

Vigotski, L. S. (2012) Aprendizagem e desenvolvimento intelectual na idade escolar. In Vigotski, L. S.; Luria, A. R.; Leontiev, A. N. (ed.) Linguagem, desenvolvimento e aprendizagem. São Paulo: Ícone. pp. $103-117$.

Wiegand, P. (2006) Learning and teaching with maps. New York: Routledge. 